EDITORIAL

\title{
A pesquisa educacional na confluência de perspectivas quanti e qualitativas
}

Ana Ivenicki a

O número 106 da revista Ensaio apresenta a possibilidade de discussão a respeito da pesquisa e da avaliação de políticas educacionais na confluência de perspectivas macro, quantitativas, de larga escala e aquelas mais qualitativas, voltadas aos espaços micro, do cotidiano das experiências educacionais provisórias e locais.

Conforme temos argumentado (IVENICKI, 2018), o reconhecimento do valor de ambas as abordagens desafia preconceitos com relação às mesmas. Os problemas de nossa educação necessitam de perspectivas que, tanto possam fornecer dados estatisticamente confiáveis, a partir de amostras representativas da população e generalizáveis para a mesma, como também de olhares sensíveis às culturas que circulam nos espaços institucionais, com suas impermanências e projetos específicos, traduzidos nas relações que se estabelecem entre os atores e as formas pelas quais vivem e significam suas realidades.

A articulação entre perspectivas quanti-quali e quali-quanti tem sido desenvolvida, nessa ótica, permitindo que, ao mesmo tempo em que uma das fases da pesquisa forneça um retrato mais amplo da problemática do estudo, a outra a complementa, ao permitir um mergulho que analise as filigranas presentes em um campo específico para a análise do tema em questão.

No caso de avaliação de políticas e práticas em educação, os olhares de ambas as perspectivas de pesquisa mostram-se úteis. Isto se deve, particularmente, ao fato de que os discursos que imbuem os documentos políticos, por exemplo, curriculares, merecerem ser analisados em relação às suas propostas, tendo em vista a forma como buscam fixar sentidos e homogeneizar visões sobre currículo e avaliação, dentre outros aspectos educacionais.

\footnotetext{
a Universidade Federal do Rio de Janeiro, Rio de Janeiro, RJ, Brasil.
} 
Entretanto, complementando essas análises em nível macro, torna-se relevante levar em conta processos de tradução e hibridização que ocorrem na contextualização dessas ideias ao nível das instituições e dos atores educacionais. Desse modo, conforme Ranniery e Macedo (2018), as ações cotidianas, passageiras, escorregadias, invisíveis acabam por se constituírem em novos modos da vida política, em espaços onde as diferenças emergem, tensionando, traduzindo, hibridizando discursos e trazendo novas possibilidades de produção de sentidos.

A relevância de pesquisas macro e micro, quanti e qualitativas, destaca-se pela própria tensão entre universalismo e relativismo. As análises de discursos políticos ao nível macro revelam, por um lado, a pretensão à hegemonização de sentidos sobre os diversos aspectos educacionais. Ao mesmo tempo, a pesquisa sobre os aspectos institucionais, qualitativos, ao nível micro, relativiza tais pretensões, destacando a dimensão local, com suas contradições, potencialidades e complexidades.

Essas questões podem ser ilustradas em artigos do presente editorial.

O foco qualitativo sobre um caso específico é realizado no artigo de Silvia Regina dos Santos Coelho e Candido Alberto Gomes, intitulado "Something new under the sun in secondary school: a case study", que analisa atividades curriculares inovadoras no contexto de uma escola pública em Curitiba que também utilizou-se da educação a distância para complementar suas atividades. Entretanto, o impacto de políticas macro é perceptível pelo que os autores indicam como o excesso de avaliações na forma de testes, na referida escola, em detrimento de avaliações que possam estimular liderança, aspectos éticos e outros necessários para a vida em sociedade. Nesse caso, ainda que a potência de perspectivas curriculares inovadoras seja ressaltada no contexto estudado, o desafio de valorizar dimensões humanas e de aprimorar o contexto escolar permanece.

Já a interseção dos níveis macro e micro, em termos de políticas públicas, é ilustrada no artigo "Remuneração docente: efeitos do plano de cargos, carreira e remuneração em contexto municipal", de Maria Dilnéia Espíndola Fernandes, Solange Jarcem Fernandes e Viviane Gregorio de Campo. O artigo mostra o movimento na carreira do professor, que se foi forjando mediante a interseção da política educacional local com a nacional, por meio da legislação. Tratou-se de pesquisa qualitativa, por meio de estudo de caso, que verificou o efeito produzido por política macro, mais especificamente pelos Planos de Cargos, Carreira e Remuneração (PCCR), implantados no município de Campo Grande, no período de 
1996 a 2016, em termos de remuneração salarial para um determinado professor, ao longo de 20 anos de carreira.

O artigo "Pacto Nacional pelo Fortalecimento do Ensino Médio - PNEM: a formação continuada na Gered de Chapecó - SC", de Sandra Maria Zardo Morescho e Nadir Castilho Delizoicov, mais uma vez, articula dados de políticas mais amplas, nesse caso sobre a formação continuada de professores ofertada pelo PNEM no período de 2014-2015, com dados relativos às percepções dos orientadores junto a professores. A interconexão entre ambos os níveis de análise ficou clara quando os impactos positivos do programa e das consequências da finalização do mesmo, trazendo temores quanto a reformas que estão por vir.

O texto de Justiani Hollas e Lucí T. M. dos Santos Bernardi, "O Exame Nacional do Ensino Médio (Enem) e as competências para uma educação estatística crítica" insere-se no foco de pesquisa qualitativa (teórica e bibliográfica) sobre a avaliação de larga escala, mais especificamente o Enem, trazendo para a discussão a problematização das ênfases do exame. Argumenta pela necessidade de inserção de aspectos para além dos conteúdos, relativos ao desenvolvimento de habilidades críticas e reflexivas, portanto focalizando os atores educacionais como peças-chave na tradução das políticas mais amplas, no cotidiano escolar.

O tema da avaliação é tratado, ao nível do impacto nos atores educacionais, no artigo "Evaluación educativa y codeterminaciones de la producción escolar", de Juan-Francisco Remolina-Caviedes. O artigo aponta, a partir do olhar do Materialismo Histórico Dialético, a forma como a avaliação, da forma pela qual tem sido concebida, emerge como entidade autônoma e soberana, resultando na opressão dos sujeitos escolares.

Cabe observar que a relevância de ambos os tipos de abordagens anteriormente referidas dá-se em um contexto em que a tecnologia tem contribuído para uma articulação, cada vez mais intensa, entre os níveis local, nacional e internacional das políticas e práticas educacionais. Como vislumbrar processos de inserção internacional curricular em perspectivas multiculturais, de valorização de processos de justiça social e de reconhecimento dos saberes plurais (MOREIRA; RAMOS, 2016), passa a ser importante dimensão a ser pesquisada. Como promover uma educação que contemple tal articulação, e que, ao mesmo tempo, reconheça a força das redes sociais, das tecnologias e de inserções do local em contextos cada vez mais amplos e internacionais, torna-se um grande desafio. 
O foco na tecnologia pode ser observado no caso do artigo "Innovation in the digital era: new labor market and educational changes", em que os autores Sidney L. M. Mello, Nicholas V. E. Ludolf, Izabela S. Rampasso e Marcelo J. Meiriño apresentam uma visão positiva da tecnologia e, por intermédio de estudo quantitativo, argumentam que o Brasil necessita incrementar a educação tecnológica, de modo a promover a competência de sua mão de obra. Ainda que, em uma perspectiva mais técnica, a educação de qualidade parece ser implícita no estudo desenvolvido, com indicações para possibilidades de utilização da tecnologia de forma alternativa e transformadora, por parte dos sujeitos institucionais.

A tecnologia ocupa, também, a atenção do artigo "A autoridade docente e a sociedade da informação: o papel das tecnologias informacionais na docência", de Leonardo Humberto Soares, Carlos Ângelo de Meneses Sousa, Ricardo Spindola Mariz e Jaci Maria Ferraz de Menezes, desta feita com as atenções para o espaço micro das instituições educacionais, analisando em que medida o desenvolvimento tecnológico reforça, ou, ao contrário, coloca em xeque a percepção do professor sobre a sua autoridade. Aponta que estudantes interagem com a tecnologia no contexto comunicacional e de lazer, reforçando a relevância do preparo do professor para que assuma o protagonismo dos significados educativos no uso da tecnologia.

Tais considerações apresentam implicações, tanto na pesquisa sobre educação a distância, como na própria educação presencial. A pesquisa sobre educação a distância, em termos da possibilidade de democratização do ensino em contextos como o brasileiro, permitindo acesso educacional para parcelas grandes da população, faz com que esse tipo de educação não possa ser ignorado. No entanto, a pesquisa no interior das instituições onde se desenvolvem programas a distância passam a revelar contradições e desafios inerentes às diferenças constitutivas dos próprios atores que participam da Educação a Distância $(\mathrm{EaD})$.

O EaD é objeto de "Políticas públicas para o ensino superior a distância: um exame do papel da Universidade Aberta do Brasil", de José Ricardo Costa de Mendonça, Danielle Cireno Fernandes, Diogo Henrique Helal e Fernanda Roda Cassundé. $\mathrm{O}$ argumento defendido vai no sentido, de um lado, de ressaltar o aspecto democratizador de acesso ao ensino superior possibilitado por esse tipo de ensino, porém, do outro, por mostrar a hegemonização de saberes aí desenvolvidos, tomando a Universidade Aberta do Brasil como foco.

Ainda versando sobre a EaD, "Interlocuções e discursos de legitimação em EaD", de Adilson Cristiano Habowski, Elaine Conte e Daniel Felipe Jacobi, aponta, 
a partir de um levantamento de teses sobre o assunto, a ambiguidade das formas pelas quais essa modalidade é analisada. Os resultados mostram, mais uma vez, os potenciais democratizadores e criativos da educação a distância, porém as formas, por vezes conteudistas e excludentes, como ela também se desenvolve.

Mais uma vez, questões relacionadas ao domínio e à presença da tecnologia, bem como aos modos de vida de docentes e discentes envolvidos podem ter impacto na permanência ou na evasão de tais programas. No ensino presencial, apresentam-se desafios com relação à forma pela qual a tecnologia será utilizada, à capacidade financeira dessas instituições e ao grau de preparo de docentes e gestores para articular tal tecnologia a formas estimulantes e criativas de desenvolvimento curricular. Nesse caso, a pesquisa das intenções mais amplas de programas que estimulam a tecnologia e as formas pelas quais se desenvolvem no contexto micro passa a ser de relevância para uma análise que permita maximizar efeitos democráticos e inclusivos.

A potência dos atores intra-escolares no desenvolvimento curricular encontra, no artigo "Uma boa gestão melhora o desempenho da escola, mas o que sabemos acerca do efeito da complexidade da gestão nesta relação?", de Beatriz Christo Gobbi, Adonai José Lacrua, Bruno Luiz Américo e Hélio Zanquetto Filho, uma evidência contundente, relativa ao papel do diretor escolar e da gestão, em toda a sua complexidade, no desempenho de estudantes em avaliações de larga escala. Ainda que não seja objeto de problematização, a avaliação de larga escala constitui-se em pano de fundo para a mensuração quantitativa da gestão e da capacidade de liderança, sendo balizadora de considerações relevantes sobre a mediação dos atores escolares no desenvolvimento cotidiano de políticas macro.

A gestão também é objeto de análise, desta feita a partir de espaços para além das instituições escolares, no artigo "A gestão democrática nos sistemas municipais de ensino do Paraná: uma análise a partir dos Conselhos Municipais de Educação" de Simone de Fátima Flach. Nesse caso, o Conselho Municipal de Educação é encarado a partir de seu papel de interferência (ou não) nos interesses que orientam as políticas públicas. Mais uma vez, o papel dos atores intra-institucionais é ressaltado, indicando em que medida a educação está sendo orientada pela gestão democrática e como a busca pela hegemonia passa pelas discussões e decisões desses mesmos atores.

Dessa forma, enquanto a pesquisa das intenções políticas mais amplas promove a análise das formas pelas quais a normatização se desenvolve, a pesquisa qualitativa, ao nível micro, desnuda vozes e identidades plurais que reinterpretam 
e reconfiguram o campo político, instabilizando a normatividade e a pretensão de universalidade do mesmo. Conforme Candau (2019), a pesquisa multicultural decolonial tem contribuído para a valorização dos espaços, das vozes e dos saberes plurais, desafiando visões colonialistas que atribuem, a padrões abstratos, eurocêntricos e hegemônicos, uma pseudouniversalidade que acaba por calar conhecimentos e saberes nativos.

Tais considerações multiculturais decoloniais encontram eco no artigo que encerra este número, "La trascendencia del sumak kawsay para nuestra comprensión de la educación, la ética y la política", de Mario Madroñero Morillo, Enma Polonia Campozano Aviles e Julio Uyaguari, que traz o foco decolonial sobre uma concepção amerindia de pensamento, rompedora da lógica hegemônica moderna, em prol de uma ontologia transformativa que ancora a política educativa a um pensamento ético e estético, em uma articulação do currículo à terra e à vida.

O exercício da pesquisa pode, portanto, ser visto, na perspectiva de nosso editorial, como promovendo o escrutínio de níveis mais amplos das políticas educacionais e, ao mesmo tempo, assumindo o compromisso da análise de possibilidades e desafios advindos dos modos em que as normatividades são reinterpretadas no contexto das identidades individuais, coletivas e institucionais plurais (IVENICKI, 2018).

Boa leitura!!! 


\section{Referências}

CANDAU, V. M. F. Pedagogias e pesquisas na perspectiva de(s)colonial. In: REUNIÃO ANUAL DA ANPED, 39., 2019, Niterói. Niterói: Universidade Federal Fluminense, 2019. Tema: Educação pública e pesquisa: ataques, lutas e resistências.

IVENICKI, A. Multiculturalismo e formação de professores: dimensões, possibilidades e desafios na contemporaneidade. Ensaio: Avaliação e Políticas Públicas em Educação, Rio de Janeiro, v. 26, n. 100, p. 1151-1167, jul. 2018. https://doi.org/10.1590/s0104-40362018002601186

MOREIRA, A. F. B.; RAMOS, R. K. Mobilidade educacional e a internacionalização dos estudos curriculares. Revista Teias, [s. l.], v. 17, n.45, p. 163-175, 2016. https://doi.org/10.12957/teias.2016.24601

RANNIERY, T.; MACEDO, E. Políticas do Vivível: diferença, teoria e democracia por vir. In: LOPES, A. C.; OLIVEIRA, A. L. A. R. M.; OLIVEIRA, G. G. S. (orgs.). Os gêneros da escola e o (im)possivel silenciamento da diferença no currículo. Recife: Ed. UFPE, 2018. p. 21-50.

\section{Informações da autora}

Ana Ivenicki: Doutora em Educação. Professora Emérita da Faculdade de Educação, da Universidade Federal do Rio de Janeiro. Pesquisadora 1A do Conselho Nacional de Desenvolvimento Científico e Tecnológico. Contato: aivenicki@gmail.com

(iD) https://orcid.org/0000-0002-7315-5500 